\section{Association among physical, psychiatric and socioeconomic conditions and WHOQOL-Bref scores}

\author{
Associação dos fatores físicos, psiquiátricos e \\ socioeconômicos e os escores do \\ WHOQOL-Bref
}

\footnotetext{
1 Departamento de Psiquiatria, Universidade Federal de São Paulo, São Paulo, Brasil.

2 Centro Universitário Hermínio Ometto, Araras, Brasil.

Correspondence S. L. Blay

Departamento de Psiquiatria Universidade Federal de São Paulo.

Rua Botucatu 740, 3o andar, São Paulo, SP 04023-900, Brasil.

blay@uol.com.br

blaysl@psiquiatria.epm.br
}

\section{Abstract}

The aim of this study is to investigate the impact of psychiatric morbidity, depression, cognitive deficit, number of self-reported illnesses and socio-demographic variables on the WHOQOLBref domain scores. WHOQOL-Bref domain scores are substantially affected by psychiatric morbidity and income. Depression, the number of selfreported illnesses and the female gender also explain the variability of other domains to a lesser extent.

Quality of Life; Depression; Comorbidity
Sergio Luís Blay 1

Marina Sthal Merlin Marchesoni 2

\section{Introduction}

The WHOQOL-Bref 1 is one of the most influential, widely used quality of life assessment instruments employed for research in internal medicine and mental health. It was designed to make international cross-culturally comparable quality of life evaluations. It assesses the individual's perceptions in the context of their culture and value systems, and their personal goals, standards and concerns. The WHOQOL instruments were developed collaboratively in a number of centers worldwide, and have been widely fieldtested $2,3,4,5,6$.

Several investigations have shown that socioeconomic variables and health comorbidities affect WHOQOL-Bref scores. Recent studies have shown that WHOQOL-Bref domain scores among the middle-aged and elderly are influenced by socio-demographic variables such as age and ethnicity ${ }^{6}$, depression $6,7,8,9$, suicidality ${ }^{10}$, psychotic symptoms 10 , depression associated with patients with chronic pain symptoms 9 , number of selfreported illnesses 8 , and self-health assessment 8 . These data suggest that the score obtained in the scale can be affected if taken into consideration. In addition, as the correlation between depression and several quality of life domains is high, some investigators have pointed out that such assessments can actually be, to a great extent, redundant 8 . 
Several situations are frequently observed among adults and elderly populations. First, the presence of multiple physical pathologies occurring simultaneously is more of a rule than an exception 11. Moreover, population studies show that, not only are depression prevalence rates high, but other psychiatric conditions are also frequent 12,13,14,15. Finally, several investigations reveal that low income and education levels are usually associated with many mortality and health problems 16,17 . This complex context can potentially influence quality of life assessments of adults and elderly people. However, within the scope of this review, there were no studies investigating whether other psychiatric conditions, not necessarily depressive, influence the test. In addition, cognitive limitations and the number of medical pathologies associated may have an effect on the scores of WHOQOL-Bref quality domains.

If the use of scores obtained in the WHOQOLBref domains is a goal to be pursued among investigations, additional clarification of factors that influence the responses in distinct areas becomes a key objective to be explained. This is the purpose of this investigation. By using a sample of middle-aged and elderly students, the present study aims to determine the level at which psychiatric comorbidities, physical comorbidities and / or socioeconomic variables explain most of the variation of the WHOQOL-Bref scores. More specifically, it is hypothesized that psychiatric morbidity affects the scores of the scale domains. Finally, it is also hypothesized that socio-demographic conditions such as gender and income, depression, cognitive deficit, and physical comorbidity is associated with the scores of each domain as well.

\section{Methodology}

\section{Instruments}

\section{- WHOQOL-Bref quality of life assessment}

To assess quality of life, the WHOQOL-Bref, an instrument proposed by the World Health Organization (WHO), was employed, translated, validated, and standardized for the Brazilian population, in an abbreviated version containing 26 questions grouped into four domains (physical, psychological, social-relational, and environmental). This instrument can be self-administered, assisted by an interviewer, or entirely administered by the interviewer. The assessment showed good reliability and validity indices. The instrument and syntax to calculate domain scores can be obtained with the WHO collaborators in Brazil (http://www.ufrgs.br/psiq). More details on the adaptation and validation study can be found in other sources 1 .

\section{- Psychiatric morbidity}

Psychiatric morbidity was assessed with the SelfReport Questionnaire (SRQ). This instrument is comprised of 20 questions and was translated and validated to be used in Brazil. It aims to detect possible individuals with non-psychotic mental disorders, which includes a group of more common psychiatric disorders, and anxiety, adjustment, somatoform and depressive disorders 18,19,20. Responses are obtained within a yes/no binary system and the total score may be obtained by adding positive responses found in the test. Test data can be treated in a dimensional or dichotomic way. In the latter case, at the $7 / 8$ cut-off point, the questionnaire shows $83 \%$ of sensitivity and $80 \%$ of specificity 18 . Psychometric properties were also tested in a sample of Brazilian elderly people and also showed high validity coefficients 20 .

\section{- Depression assessment}

The presence of depression was assessed with the Portuguese version of the Beck Depression Inventory (BDI) 21. This instrument is comprised of 21 items, and was translated into Portuguese. It aims to assess possible people with depressive symptoms 22 . The self-administered questionnaire shows a response structure that identifies the presence and intensity of symptoms present in the last month. A total score is obtained by adding the scores noted in each item. The total value may vary between 0 and 63 points. People who achieved a score equal to or higher than 21 points in the test delimited the presence of depression for different samples 23 .

\section{- Assessment of cognitive performance}

Assessment of cognitive performance was conducted using the Mental Status Questionnaire (MSQ), designed by Kahn et al. 24 and employed as a tracking test to detect possible dementia cases. This instrument is comprised of 10 questions that aim to assess several functions of cognitive functioning. Items are assessed in a simple, correct/incorrect binary system, and a general score can be achieved from the sum of incorrect responses obtained in the test. The Portuguese version of the test was translated and validated, and satisfactory validation coefficients were obtained to be used in elderly populations 25 . In this study, 
we used the cut-off point lerror $/ 2+$ errors to detect possible cases with cognitive impairment.

\section{- Number of self-reported clinical illnesses}

Information on physical health was obtained with a questionnaire that investigates the presence of the 15 frequent medical problems 26 . Selfreported medical problems were considered to be present if they had occurred in the previous six months and medical guidance with or without the use of medications had been obtained. A new variable named number of illnesses was created for this study, and it was comprised of the sum of self-reported illnesses that were simultaneously present in the same individual. The following conditions were analyzed: rheumatism, bronchitis, hypertension, heart problems, diabetes, cerebral vascular disease, dermatological problems, spine diseases, gastro-intestinal/digestive diseases, urinary infection, pneumonia, kidney diseases, osteoporosis, cancer and prostatic problems (only for men).

\section{- Participants}

Universities were selected according to the following criteria: to be a teaching institution operating in the city of São Paulo, whose educational program focuses on the updating of knowledge and new developments; to have been active for more than 10 years; to have at least $30 \mathrm{stu}$ dents enrolled per class, with courses offered to people of both sexes, and which can be either private or free. According to these criteria, the Open Universities for the Elderly of the Federal University of São Paulo (UNIFESP) and the São Paulo Pontifical Catholic University (PUC-SP) in the city of São Paulo were included. A total of 90 individuals of both sexes, who were beginning the activities proposed by the selected universities, participated in this study. In all, there were 55 UNIFESP students and 35 PUC-SP students. In general their personal income (minimum wages per month) were higher as compared to the total city population (sample: $25 \%$ receive $0-5$ minimum wages per month; city of São Paulo: $75 \%$ receive 0-5 minimum wages per month) 27 .

\section{- Additional information}

The following additional information about socio-demographic characteristics was obtained with the structured questionnaire: sex, age in years $(<60,60-65,>65)$, level of education in years $(0-8,9-11,>11)$, personal income in minimum wages per month $(0-5 ; 5-10 ;>10)$, and educational center (PUC-SP, UNIFESP).

\section{Procedure}

According to university norms, the instrument should be applied at times that did not overlap with the teaching activities. Thus, it was decided that the instruments should be filled out by the interviewee at any time and handed in within one week, the deadline for the reply and return of the protocols. At the first group contact with the elderly, the Informed Consent Form was read and the questionnaires were subsequently handed out. Questionnaires were self-administered and, in case one had difficulty reading, due to low level of education, sight impairment or any other limitation, the instrument would be applied by another program participant, intentionally selected, or by a family member. This project was approved by the UNIFESP Ethics Committee.

\section{- Statistical analysis}

The results were initially analyzed with descriptive techniques (means, standard deviations, and frequencies). Subsequently, the chi-square test was employed to compare frequencies between centers. To compare scoring between the SRQ, BDI and MSQ quality of life scales and genders, the Mann-Whitney test was employed. To analyze the influence of independent variables of interest on quality of life scores, (univariate and multivariate) multiple linear regression analysis was employed, with the response variable transformed into ranks, due to the absence of normal distribution. Univariate analyses were initially performed for the multivariate analysis procedure. Variables that reached a value of $\mathrm{p}<0.20$, considered a potential predictor, were incorporated into the second phase of the analysis, that is, the multivariate analysis. The final selection of variables in the linear regression model was carried out with the stepwise criterion that allows for a good model selection when generating hypothesis and controlling for multicollinearity. The significance level adopted for statistical tests was $5 \%(p<0.05)$. The SAS System for Windows software, version 6.12 (SAS Inst., Cary, USA), was used for the statistical analysis.

\section{Results}

A total of 90 people were examined at both teaching institutions. Except for sex, there was no difference between users of both institutions in terms of age, level of education, and personal income. Thus, groups were analyzed together. Socio-demographic and clinical characteristics are shown on Table 1. 
Socio-demographic and clinical characteristics of the sample *

\begin{tabular}{|c|c|c|}
\hline Characteristics & n & $\%$ \\
\hline \multicolumn{3}{|l|}{ Sex } \\
\hline Male & 14 & 15.6 \\
\hline Female & 76 & 84.4 \\
\hline \multicolumn{3}{|l|}{ Age (years) } \\
\hline$<60$ & 31 & 34.4 \\
\hline $60-65$ & 21 & 23.3 \\
\hline$>65$ & 38 & 42.2 \\
\hline \multicolumn{3}{|c|}{ Level of education (years of study) } \\
\hline $0-8$ & 25 & 28.4 \\
\hline $9-11$ & 35 & 39.4 \\
\hline$>11$ & 28 & 31.8 \\
\hline \multicolumn{3}{|c|}{ Personal income (minimum wages } \\
\hline \multicolumn{3}{|l|}{ per month) } \\
\hline $0-5$ & 31 & 39.2 \\
\hline $5-10$ & 22 & 27.8 \\
\hline$>10$ & 26 & 33.0 \\
\hline \multicolumn{3}{|c|}{ Educational center } \\
\hline UNIFESP & 55 & 61.1 \\
\hline PUC-SP & 35 & 38.9 \\
\hline \multicolumn{3}{|l|}{$\mathrm{SRO}$} \\
\hline Negative & 75 & 83.3 \\
\hline Positive & 15 & 16.7 \\
\hline \multicolumn{3}{|l|}{ BDI } \\
\hline Negative & 81 & 90.0 \\
\hline Positive & 9 & 10.0 \\
\hline \multicolumn{3}{|l|}{ MSQ } \\
\hline Negative & 75 & 84.3 \\
\hline Positive & 14 & 15.7 \\
\hline
\end{tabular}

* Incomplete information for some variables.

BDI: Beck Depression Inventory; MSQ: Mental Status Questionnaire; PUC-SP: São Paulo Pontifical Catholic University; SRQ: Self-Report Questionnaire; UNIFESP: Federal University of São Paulo.

The prevalence of medical illnesses assessed was high, with the following standing out: hypertension (44.3\%), rheumatism (35.3\%), osteoporosis $(31.4 \%)$, spine $(21.8 \%)$ and dermatological conditions (20.6\%). As expected, the number of self-reported medical illnesses simultaneously present in individuals is high. Of all the 90 people assessed, $94.3 \%$ have 2 or + diseases; $81.7 \%$ have 3 or + diseases; and $70.2 \%$ have 4 or + diseases. The average found was $4.76(\mathrm{SD}=2.17)$.

The average of WHOQOL-Bref domains for the general sample and in relation to SRQ and BDI scores are shown on Table 2. Comparative analysis of scores in the four domains did not show statistical differences between the genders. MSQ data were not statistically different and are not shown in the table.

An exploratory analysis was performed to try to understand the relationship of socio-demographic and health characteristics to quality of life scores. To achieve this, a univariate linear regression analysis was carried out with each independent variable (sex, age, level of education, personal income, educational center, SRQ-20, BDI, MSQ, and number of illnesses) and also the 4 WHOQOL-Bref quality of life domains (transformed into ranks due to the absence of normal distribution) analyzed as dependent variables. As a result, it was found that sex, age, personal income, family income, educational center, number of illnesses, MSQ, and BDI did not show statistical significance and did not contribute substantially to explain the variation in physical domain scores. Secondly, sex, age, level of education, family income, educational center, and MSQ were not statistically significant and did not contribute substantially to explain variations in psychological domain scores.

Subsequently, it was observed that sex, age, level of education, personal income, family income, educational center, number of illnesses, and MSQ were not statistically significant and did not contribute substantially to explain the variation in social domain scores. Lastly, sex, age, level of education, educational center, number of illnesses, MSQ, and BDI, were not statistically significant and did not contribute substantially to explain the variation in environmental domain scores.

For the subsequent multivariate analysis, using $\mathrm{p}<0.20$ from the univariate analysis as inclusion criterion, a total of seven variables were retained in the model to analyze the physical domain. Of these, three examine socio-demographic variables (sex, level of education, and family income) and four measure physical and psychological health aspects (number of diseases, BDI, and SRQ-20). For the psychological domain, eight variables were retained in the model. Of these, four examine socio-demographic variables (sex, age, level of education, and personal income), while the other four measure physical and psychological health aspects (number of illnesses, MSQ, BDI, and SRQ). For the social domain, six variables were retained in the model. Of these, three examine socio-demographic variables (age, level of education, and personal income) while the other three measure physical and psychological health aspects (number of illnesses, BDI, and SRQ). For the environmental domain, four variables were retained in the model. Of these, three 
Means of WHOQOL-Bref domains for the total sample and in relation to Self-Report Questionnaire (SRQ) and Beck Depression Inventory (BDI) scores *.

\begin{tabular}{|c|c|c|c|c|c|c|c|}
\hline & $\mathbf{N}$ & Mean & SD & Minimum & Median & Maximum & $\mathrm{p}$-value \\
\hline \multicolumn{8}{|c|}{ Means of WHOQOL-Bref } \\
\hline \multicolumn{8}{|l|}{ Domain } \\
\hline Physical & 86 & 59.90 & 9.96 & 35.71 & 60.71 & 75.00 & \\
\hline Psychological & 86 & 61.00 & 11.62 & 33.33 & 62.50 & 87.50 & \\
\hline Social & 86 & 67.83 & 19.06 & 16.67 & 66.67 & 100.00 & \\
\hline Environmental & 86 & 66.48 & 13.69 & 31.25 & 68.75 & 93.75 & \\
\hline \multicolumn{8}{|c|}{ Means of WHOQOL-Bref in relation to SRQ } \\
\hline \multicolumn{8}{|c|}{ cut-off point $(\geq 8)$} \\
\hline \multicolumn{8}{|l|}{ Physical } \\
\hline Negative & 71 & 62.69 & 7.76 & 42.86 & 64.29 & 75.00 & $<0.001$ \\
\hline Positive & 15 & 46.67 & 8.59 & 35.71 & 46.43 & 60.71 & \\
\hline \multicolumn{8}{|l|}{ Psychological } \\
\hline Negative & 71 & 63.66 & 10.09 & 41.67 & 62.50 & 87.50 & $<0.001$ \\
\hline Positive & 15 & 48.39 & 10.22 & 33.33 & 50.00 & 66.67 & \\
\hline \multicolumn{8}{|l|}{ Social } \\
\hline Negative & 71 & 72.42 & 16.54 & 25.00 & 75.00 & 100.00 & $<0.001$ \\
\hline Positive & 15 & 46.11 & 15.06 & 16.67 & 50.00 & 66.67 & \\
\hline \multicolumn{8}{|l|}{ Environmental } \\
\hline Negative & 71 & 68.38 & 13.23 & 37.50 & 68.75 & 93.75 & 0.011 \\
\hline Positive & 15 & 57.50 & 12.54 & 31.25 & 59.38 & 71.88 & \\
\hline \multicolumn{8}{|c|}{ Means of WHOQOL-Bref in relation to BDI } \\
\hline \multicolumn{8}{|l|}{ cut-off point ( $\geq 21)$} \\
\hline \multicolumn{8}{|l|}{ Physical } \\
\hline Negative & 78 & 60.64 & 9.36 & 35.71 & 60.71 & 75.00 & 0.059 \\
\hline Positive & 8 & 52.68 & 13.19 & 35.71 & 51.79 & 71.43 & \\
\hline \multicolumn{8}{|l|}{ Psychological } \\
\hline Negative & 78 & 62.48 & 10.68 & 40.00 & 62.50 & 87.50 & 0.001 \\
\hline Positive & 8 & 46.56 & 11.06 & 33.33 & 43.75 & 62.50 & \\
\hline \multicolumn{8}{|l|}{ Social } \\
\hline Negative & 78 & 70.73 & 16.99 & 25.00 & 75.00 & 100.00 & $<0.001$ \\
\hline Positive & 8 & 39.58 & 15.27 & 16.67 & 37.50 & 58.33 & \\
\hline \multicolumn{8}{|l|}{ Environmental } \\
\hline Negative & 78 & 66.93 & 14.01 & 31.25 & 68.75 & 93.75 & 0.336 \\
\hline Positive & 8 & 62.11 & 9.51 & 46.88 & 64.06 & 71.88 & \\
\hline
\end{tabular}

* p-value from the Mann-Whitney test to compare scores between the SRQ and BDI groups.

examine socio-demographic variables (level of education, personal income, and family income), while one measures mental health aspects (SRQ). Results of the regression performed with the stepwise method, including socio-demographic and health variables, are shown on Table 3.

Based on the results, the following variables were found to be significantly and concomitantly associated with WHOQOL-Bref quality of life scores: (1) physical quality of life (SRQ: SRQ cases have a score of 35.2 ranked units lower than noncases); (2) psychological quality of life (sex: wom- en have a score of 14.8 ranked units lower than men; SRQ: SRQ cases have a score of 27.7 ranked units lower than non-cases; number of diseases: for each illness, the quality of life score decreases 0.24 ranked units); (3) social quality of life (SRQ: SRQ cases have a score of 23.5 ranked units lower than non-cases; BDI: BDI cases have a score of 27.8 ranked units lower than non-cases); (4) environmental quality of life (personal income: people with an income of between 0-5 minimum wages per month have a score of 27.4 ranked units lower than those with an income greater 
Multiple linear regression analysis results for the four WHOQOL-Bref domains.

\begin{tabular}{|c|c|c|c|}
\hline Variables & Estimate (SE) & p-value & $\mathrm{R}^{2}(\%)$ \\
\hline \multicolumn{4}{|l|}{ Physical $(n=81)$} \\
\hline Intercept & $49.98(2.59)$ & $<0.001$ & \\
\hline \multicolumn{4}{|l|}{ 1. $\mathrm{SRO}$} \\
\hline \multicolumn{4}{|l|}{ Non-case } \\
\hline Case & $-35.19(6.23)$ & $<0.001$ & 28.80 \\
\hline Total variance & & & 28.80 \\
\hline \multicolumn{4}{|l|}{ Psychological $(n=68)$} \\
\hline Intercept & $87.74(12.56)$ & $<0.001$ & - \\
\hline \multicolumn{4}{|l|}{ 1. SRQ } \\
\hline \multicolumn{4}{|l|}{ Non-case } \\
\hline Case & $-27.74(6.85)$ & $<0.001$ & 22.85 \\
\hline 2. Number of illnesses for each illness (ranks) & $-0.24(0.10)$ & 0.021 & 6.50 \\
\hline \multicolumn{4}{|l|}{ 3. Sex } \\
\hline \multicolumn{4}{|l|}{ Male } \\
\hline Female & $-14.77(6.44)$ & 0.025 & 5.37 \\
\hline Total variance & & & 34.72 \\
\hline \multicolumn{4}{|l|}{ Social $(n=69)$} \\
\hline \multicolumn{4}{|l|}{ 1. $S R Q$} \\
\hline \multicolumn{4}{|l|}{ Non-case } \\
\hline Case & $-23.51(7.14)$ & 0.002 & 23.29 \\
\hline \multicolumn{4}{|l|}{ 2. BDI } \\
\hline \multicolumn{4}{|l|}{ Non-case } \\
\hline Case & $-27.80(8.66)$ & 0.002 & 10.36 \\
\hline Total variance & & & 33.65 \\
\hline \multicolumn{4}{|l|}{ Environmental $(n=72)$} \\
\hline Intercept & $37.80(4.21)$ & $<0.001$ & - \\
\hline \multicolumn{4}{|l|}{ 1. Personal income (minimum wages) } \\
\hline \multicolumn{4}{|l|}{$0-5$} \\
\hline $5-10$ & $-1.10(6.30)$ & 0.862 & - \\
\hline$>10$ & $27.37(5.95)$ & $<0.001$ & 22.27 \\
\hline \multicolumn{4}{|l|}{ 2. SRQ } \\
\hline \multicolumn{4}{|l|}{ Non-case } \\
\hline Case & $-21.61(6.90)$ & 0.003 & 9.81 \\
\hline Total variance & & & 32.08 \\
\hline
\end{tabular}

BDI: Beck Depression Inventory; Estimate: value of the angular coefficient " $b$ " on the regression line $\mathrm{Y}=\mathrm{a}+\mathrm{bX}$, where " $\mathrm{a}$ " = intercept (1st value); SE: standard error; SRQ: Self-Report Questionnaire; R2: coefficient of determination (\% of variability explained by the variable).

Note: Dependent variable - WHOQOL-Bref domain scores (transformed into ranks); stepwise criterion for variable selection.

than ten minimum wages per month; SRQ: SRQ cases have a score of 21.6 ranked units lower than non-cases) (Table 4).

\section{Discussion}

Results obtained in this study indicate that psychiatric morbidity affects all domains assessed by the scale. In three of them - physical, psychological and social - the variability explained by the variable was high, $28.8 \%, 22.85 \%$ and $23.29 \%$ respectively. In the environmental domain, the impact was comparatively lower, $9.81 \%$. Depression, as assessed with the BDI, is associated with the assessment of the social domain, explaining $10.36 \%$ of the variability. In other comparable studies, all the WHOQOL-Bref domains and the 
Factors associated with self-rated quality of life and satisfaction with health.

\begin{tabular}{|c|c|c|}
\hline Variables & Unadjusted OR $(95 \% \mathrm{Cl})$ & Adjusted OR $(95 \% \mathrm{Cl})$ \\
\hline \multicolumn{3}{|c|}{ How would you rate your quality of life? * } \\
\hline \multicolumn{3}{|l|}{ SRQ } \\
\hline Non-cases & 1.00 & 1.00 \\
\hline Cases & $0.05(0.01-0.19)$ ** & $0.07(0.02-0.29) * \star$ \\
\hline \multicolumn{3}{|l|}{$\mathrm{BDI}$} \\
\hline Non-cases & 1.00 & 1.00 \\
\hline Cases & $0.10(0.02-0.44) * \star$ & $0.22(0.03-1.35)$ \\
\hline \multicolumn{3}{|c|}{ How satisfied are you with your health? ${ }^{\star \star \star}$} \\
\hline \multicolumn{3}{|l|}{$\mathrm{SRQ}$} \\
\hline Non-cases & 1.00 & 1.00 \\
\hline Cases & $0.15(0.04-0,49) * *$ & $0.45(0.10-2.17)$ \\
\hline \multicolumn{3}{|l|}{$\mathrm{BDI}$} \\
\hline Non-cases & 1.00 & 1.00 \\
\hline Cases & $0.30(0.07-1.21)$ & $0.44(0.07-2.63)$ \\
\hline \multicolumn{3}{|c|}{ Number of diseases } \\
\hline$\leq 3$ & 1.00 & 1.00 \\
\hline$\geq 4$ & $0.27(0.09-0.79) \#$ & $0.32(0.10-1.02)$ \\
\hline
\end{tabular}

BDI: Beck Depression Inventory; SRQ: Self-Report Questionnaire.

* Adjusted by SRQ, BDI, gender and education;

** $\mathrm{p}=0.001$;

*** Adjusted by SRQ, BDI, number of diseases, education (gender excluded of analysis due to reduced number of cases);

$\# \mathrm{p}=0.01$.

BDI assessments were inversely and significantly associated 6 .

One negative finding of interest is that minor cognitive deficits, analyzed with the MSQ, were not associated with quality of life domains, both in the univariate and multivariate analyses. Unlike depression, the cognitive changes observed in this sample probably do not bring objective or subjective complaints that can be detected by the scale. The number of self-reported illnesses is associated with the psychological domain's performance. The variability explained was $6.5 \%$. This result was somewhat surprising, since the majority of illnesses were expected to have substantially influenced the quality of life assessment in general. The nature of the sample and the relatively benign and asymptomatic course of some illnesses, such as hypertension and osteoporosis, may explain the low impact on quality of life scores.

The female gender is associated with the psychological domain assessment and explains $5.47 \%$ of the score variability. Briscoe 28 , while studying people's ways of expressing their health conditions, found more availability to bring up subjectivity issues, and also more easiness among women to express their inner experiences, which may influence on the subjective perception and sensibility. This phenomenon can justify the influence of sex on the performance of this domain.

Personal income is independently and significantly associated with the environmental domain. Individuals with an income above 10 minimum wages per month score higher on the scale and have an explained variation of $22.3 \%$, compared to those with an income of between 0 and 5 minimum wages per month. Berkman 16 already emphasized the importance of socioeconomic aspects and their impact on morbidity and mortality in the health area. Economic conditions may favor the organization of more ecological and safer environmental contexts, which will certainly be necessary for people's well-being. Elderly people are undoubtedly more vulnerable to environmental changes. Economic capacity may minimize these impacts, which can be inferred from the results.

One of the main hypotheses of this study was confirmed, that is, that several psychological conditions, apart from depression, can affect the scale's performance in general. Psychiatric 
morbidity affected the four domains and, more specifically, the physical, psychological and social ones. In contrast, depression was only associated with the psychological domain, probably due to the more benign nature of the cases. Individuals' subjective perception of the several aspects of their lives is the key point to assess quality of life. Depression has always been considered a paradigm to study the interface between subjective states and quality of life assessment. Psychopathology of depressive states usually compromises the observation of inner and outer reality by individuals suffering from this condition. However, the new aspect found in this study is that there are a great number of psychic manifestations, in addition to depression, that can affect scale assessment.

In the theoretical sphere, it is debatable if the assessment of quality of life evaluates aspects that are distinct from depression or if they are redundant. Data from this study indicate the need to investigate further other psychiatric conditions to verify whether theoretical constructs of quality of life are distinct from those that assess psychopathology. Other investigators have already suggested this in relation to depression 8 .

Other hypotheses were also confirmed. Income is substantially associated with the environmental domain. This finding may be another piece of evidence for the role of economic aspects associated not only with morbid-mortality, but also with quality of life. The number of selfreported illnesses and gender are related to the performance in the psychological domain to a lesser extent. Negative data of interest is that minor cognitive deficits did not interfere with quality of life scores.

Results from this study suggest that the impact of the variables studied on quality of life is important. Non-depressive psychological problems, income, gender and number of related physical illnesses can also influence the individual's perception of their own existence, and, as a result, the quality of life assessments. At this moment, however, it does not seem justifiable to make score corrections in the domains, to the detriment of these problems. This line of argu- ment is based on the possibility that domains do not assess independent quality of life aspects, but rather phenomena that interpenetrate and interconnect with each other. The nature of this tapestry needs to be clarified better with new studies.

Data from this study must be analyzed with caution, since there are limitations. The first one is about the non-clinical sample profile, which can provide a more favorable view on physical and mental health conditions. However, among the elderly, the prevalence of medical conditions is high, as observed in this study. This reflects, to some extent, a certain clinical reality of this age group, and also minimizes bias originating from exclusively analyzing healthy individuals. Health assessments were self-reported. Nonetheless, there is evidence in the literature that the information thus obtained in this population is not valid 29,30. The sample employed in this study, which is comprised of individuals willing to study and learn and also showing autonomy, favored the analysis of healthier people. Results cannot be generalized and must be examined with caution, including impoverished individuals from a health and socioeconomic point of view. Finally, the sample size of this study is rather is small.

In brief, this sample showed WHOQOL-Bref domain scores that are substantially affected by psychiatric morbidity in three out of four scale domains: physical, social and psychological. Personal income explains most of the variability in the environmental domain. Depression, number of self-reported illnesses and the female gender also explain the variability of some domains to a lesser extent. Given these results, the assessment of quality of life obtained from the WHOQOL-Bref must be interpreted taking into consideration some of these clinical and socioeconomical variables. This information may be important to patients, practitioners, and to researchers involved in this area. In addition, as interactions must be reciprocal, this may help to analyze whether domains are distinct constructs or redundant, due to certain health and socioeconomic conditions. 


\section{Resumo}

O objetivo deste estudo é o de investigar o impacto da morbidade psiquiátrica, depressão, comprometimento cognitivo, número de doenças autorreferidas e variáveis sociodemográficas nos escores do WHOQOL-Bref. Os escores dos domínios do WHOQOL-Bref estão associados à morbidade psiquiátrica e renda. A depressão, o número de doenças autorreferidas e o sexo feminino também explicam a variabilidade nos outros domínios, porém em menor grau.

Qualidade de Vida; Depressão; Comorbidade

\section{Contributors}

S. L. Blay participated in the design and analysis of the study and the article write up. M. S. M. Marchesoni collaborated in the design, data collection and analysis and write up.

\section{Acknowledgments}

To Open Universities for the Elderly of the Federal University of São Paulo (UNIFESP) and the São Paulo Pontifical Catholic University (PUC-SP), for allowing us to conduct this study. To the National Research Council (CNPq) for a research grant for Dr. Sergio Luís Blay (n. 300235/2008-9).

\section{References}

1. Fleck MP, Louzada S, Xavier M, Chachamovich E, Vieira G, Santos L, et al. Aplicação da versão em português do instrumento abreviado de avaliação da qualidade de vida WHOQOL-Bref. Rev Saúde Pública 2000; 34:178-83.

2. Jaracz K, Kalfoss M, Górna K, Baczyk G. Quality of life in Polish respondents: psychometric properties of the Polish WHOQOL-Bref. Scand J Caring Sci 2006; 20:251-60.

3. Skevington SM, Lotfy M, O'Connell KA; WHOQOL Group. The World Health Organization's WHOQOLBref quality of life assessment: psychometric properties and results of the international field trial. A report from the WHOQOL group, 2004. Qual Life Res 2004; 12:299-310.

4. Hwang HF, Liang WM, Chiu YN, Lin MR. Suitability of the WHOQOL-BREF for community-dwelling older people in Taiwan. Age Ageing 2003; 32:593600.

5. Chachamovich E, Trentini C, Fleck MP. Assessment of the psychometric performance of the WHOQOLBref instrument in a sample of Brazilian older adults. Int Psychogeriatr 2007; 19:635-46.
6. Berlim MT, Pavanello DP, Caldieraro MA, Fleck MP. Reliability and validity of the WHOQOL-Bref in a sample of Brazilian outpatients with major depression. Qual Life Res 2005; 14:561-4.

7. Xavier FM, Ferraza MP, Argimon I, Trentini CM, Poyares D, Bertollucci PH, et al. The DSM-IV "minor depression" disorder in the oldest-old: prevalence rate, sleep patterns, memory function and quality of life in elderly people of Italian descent in Southern Brazil. Int J Geriatr Psychiatry 2002; 17:107-16.

8. Naumann VJ, Byrne GJ. WHOQOL-Bref as a measure of quality of life in older patients with depression. Int Psychogeriatr 2004; 16:159-73.

9. Aigner M, Förster-Streffleur S, Prause W, Freidl M, Weiss M, Bach M. What does the WHOQOL-Bref measure? Measurement overlap between quality of life and depressive symptomatology in chronic somatoform pain disorder. Soc Psychiatry Psychiatr Epidemiol 2006; 41:81-6.

10. Berlim MT, McGirr A, Fleck MP. Can sociodemographic and clinical variables predict the quality of life of outpatients with major depression? Psychiatry Res 2008; 160:364-71. 
11. Blay SL, Andreoli SB, Fillenbaum GG, Gastal FL. Equity of access to outpatient care and hospitalization among older community residents in Brazil. Med Care 2008; 46:930-7.

12. Herrera Jr. E, Caramelli P, Silveira AS, Nitrini R. Epidemiologic survey of dementia in a communitydwelling Brazilian population. Alzheimer Dis Assoc Disord 2002; 16:103-8.

13. Andrade L, Walter EE, Gentil V, Laurenti R. Prevalence of ICD-10 mental disorders in a catchment area in the city of São Paulo, Brazil. Soc Psychiatry Psychiatr Epidemiol 2002; 37:316-25.

14. Blay SL, Andreoli SB, Fillenbaum GG, Gastal FL. Depression morbidity in later life: prevalence and correlates in a developing country. Am J Geriatr Psychiatry 2007; 15:790-9.

15. Scazufca M, Menezes PR, Vallada HP, Crepaldi AL, Pastor-Valero M, Coutinho LM, et al. High prevalence of dementia among older adults from poor socioeconomic backgrounds in São Paulo, Brazil. Int Psychogeriatr 2008; 20:394-405.

16. Berkman LF. The association between educational attainment and mental status examinations: of etiologic significance of senile dementia or not? J Chronic Dis 1986; 39:171-5

17. Minicuci N, Maggi S, Pavan M, Enzi G, Crepaldi G. Prevalence rate and correlates of depressive symptoms in older individuals: the Veneto Study. J Gerontol A Biol Sci Med Sci 2002; 57:M155-61.

18. Mari JJ, Williams P. A validity study of a psychiatric screening questionnaire (SRQ-20) in primary care in the city of São Paulo. Br J Psychiatry 1986; 148:23-6.

19. Patel V, Araya R, Chowdhary N, King M, Kirkwood B, Nayak S, et al. Detecting common mental disorders in primary care in India: a comparison of five screening questionnaires. Psychol Med 2008; 38:221-8.

20. Scazufca M, Menezes PR, Vallada H, Araya R. Validity of the self reporting questionnaire-20 in epidemiological studies with older adults: results from the São Paulo Ageing \& Health Study. Soc Psychiatry Psychiatr Epidemiol 2009; 44:247-54.

21. Beck AT, Rush AJ, Shaw BF, Emeery G. Terapia cognitiva da depressão. Rio de Janeiro: Jorge Zahar Editor; 1982.
22. Gorenstein C, Andrade L, Vieira Filho AHG, Tung TC, Artes R. Psychometric properties of the Portuguese version of the Beck Depression Inventory on Brazilian college students. J Clin Psychol 1999; 55:553-62.

23. Kendall PC, Hollon SD, Beck AT, Hammen CL, Ingram RE. Issues and recommendations regarding use of the Beck Depression Inventory. Cognit Ther Res 1987; 11:289-99.

24. Kahn RL, Goldfarb AI, Pollack M, Peck A. Brief objective measures for the determination of mental status in the aged. Am J Psychiatry 1960; 117:326-8.

25. Blay SL, Mari JJ, Ramos LR, Ferraz MPT. Validity of the Brazilian version of the Mental Status Questionnaire as a screening test for dementia among elderly urban subjects: a pilot study. Int J Geriatr Psychiatry 1991; 6:779-85.

26. Caughey GE, Vitry AI, Gilbert AL, Roughead EE. Prevalence of comorbidity of chronic diseases in Australia. BMC Public Health 2008; 8:221.

27. Fundação Sistema Estadual de Análise de Dados. Distribuição dos domicílios, por faixas de renda per capita, segundo distritos: Município de São Paulo, 2000. http://www.seade.gov.br/produtos/ $\mathrm{msp} / \mathrm{ren} / \mathrm{ren} 2 \_001$ (accessed on 18/Nov/2009).

28. Briscoe ME. Sex differences in perception of illness and expressed life satisfaction. Psychol Med 1978; 8:339-45.

29. Beckett M, Weinstein M, Goldman N, Yu-Hsuan L. Do health interview surveys yield reliable data on chronic illness among older respondents? Am J Epidemiol 2000; 151:315-23.

30. Bergmann MM, Byers T, Freedman DS, Mokdad A. Validity of self-reported diagnoses leading to hospitalization: a comparison of self-reports with hospital records in a prospective study of American adults. Am J Epidemiol 1998; 147:969-77.

Submitted on 15/Mar/2010

Final version resubmitted on 12/Jun/2010 Approved on 23/Dec/2010 